Please quote as: Janson, A.; Peters, C. \& Leimeister, J. M. (2015): The efficient provision of culture-sensitive services - a modularization approach. In: 3rd international conference on Serviceology (ICServ 2015), San Jose, CA, USA. 


\title{
The Efficient Provision of Culture-sensitive Services - a Modularization Approach
}

\author{
Andreas Janson ${ }^{1}$, Christoph Peters ${ }^{1,2}$ and Jan Marco Leimeister ${ }^{1,2}$ \\ ${ }^{1}$ Kassel University, Information Systems, Pfannkuchstr. 1, 34121 Kassel, Germany \\ Tel: +49 5618046321 , Fax: +49 561 8046067, E-mail: andreas.janson@uni-kassel.de \\ 2 University of St. Gallen, Institute of Information Management, Switzerland
}

\begin{abstract}
This paper presents first guidelines for the cultural adaptation and efficient global provision of services. For this purpose, it elaborates on how to consider culture-specific components of a service on the basis of systematic service modularization. This is illustrated by the example of an IT-mediated learning service, which is usually perceived differently in diverse cultures. To this end, a process model is described based on culture theory and systematic modularization in order to identify culture-specific and culture-independent components of a learning service for its consideration within global service provision. This contribution to practice is complemented by the theoretical contribution of the inclusion of culture-theoretical components into service modularization.
\end{abstract}

\section{Keywords:}

service modularization, culture, learning service

\section{INTRODUCTION}

Globalization has become a frequently discussion topic for companies. Therefore, the global education and training of employees is a critical success factor in the context of globalization. These market needs also affect the service industry. Thus currently, about one in four German education providers exports the German education abroad, which is assumed a growing need [1]. Against this background, the relevance of technologymediated learning services need to be considered in order to allow cost advantages in terms of education export [2].

However, problems may arise when exporting a service. Services such as the here mentioned education and vocational trainings cannot be adopted one-to-one from for example Germany by another country. There are significant inhibitory factors that complicate the export of services. These include, e.g., legal barriers or the adaptation of the service to the target market, with the latter constituting major problems for many education and vocational training providers [2]. In addition to the linguistic assimilation, a cultural understanding of the target country is an important factor when adapting such a service [2]. Culture, hereby defined as the shared values of a group of individuals [3], is a construct that can adversely affect the perception of a service [4-6]. This also applies to technology-mediated learning services [7, 8], e.g., in the context of global differences in learning and teaching approaches [9].

The enabling of a culture-sensitive adaptation and provision of a service therefore relies on the concept of modularization. The selective identification of standardized modules firstly allows the implementation of cost advantages. Additionally, the modularization offers potentials in order to meet the challenges regarding the culture-sensitive adaptation of a service described above [10]. The present paper aims at formulating first guidelines on how to achieve the culture-sensitive provision of a service by means of systematic modularization. This contribution is therefore based on the following research questions $(R Q)$ :

$R Q 1:$ How can culture be considered in terms of service modularization?

RQ2: How should a methodology be designed in order to include culture systematically in the modularization process?

The theoretical contribution of this paper lies in the consideration of culture-theoretical principles for the modularization of services, while the practical contribution lies in the provision of a systematic practical method allowing the export of a technology-mediated learning service. In order to achieve the aim of this paper and to answer the above research questions, this article is based on theory-driven, design-oriented research [11-13] and is structured as follows. First, the theoretical principles concerning IT-mediated learning services, culture, and service modularization are presented. Based on this, the third chapter illustrates how national culture can be used as a starting point for the systematic modularization of technology-mediated learning services. Section 3.1 elaborates on how culture influences such learning services. Following, the methodology is described in Section 3.2, before being exemplarily evaluated in Section 3.3, using the model of a service export from Germany to China. The fourth chapter discusses according results. The paper concludes with limitations and possible future research in Chapter 5 and concludes in Chapter 6.

\section{THEORETICAL BACKGROUND}

\subsection{Technology-mediated Learning Services}

Technology-mediated learning services (TMLS) are subsequently defined as environments of technologysupported interaction between learners and learning materials such as scripts or assignments, fellow learners, and/or lecturers [14]. These types of services are becoming more and more relevant and should be regarded as socially necessary. They are complex services, namely consisting of IT parts as well as non-IT parts that are characterized by a strong focus on people and knowledge intensity. Referring to IT support, these learning services are in practice often equated with elearning and their according terms are used interchangeably [15]. It should be noted that such TMLS work in many forms and may combine different learning styles and methods in practice. Therefore, these learning services are referred to as blended learning concepts, which can by way of example be configured as follows [16]:

- Web or computer-based

- Asynchronous or synchronous

- Lecturer-centered or learner self-directed

- Individual or collaborative learning

This variety of options for service configuration and their consideration poses particular challenges for research. In order to address these challenges, the subsequent sections refer to the theoretical principles of Gupta and Bostrom [16], who have developed a holistic framework 
ICServ2015, 022, v2: 'The efficient p...' for TMLS based on adaptive structuration theory (AST) [17]. AST allows to examine the complex relationships between technology in social structures, which were first investigated in group decision support systems and their use in organizations [17]. The framework incorporates input and output factors of the service and, in contrast to previous research methods, the learning process, which is particularly important for the actual learning outcomes and thus the quality and productivity of the service [14, 18, 19].

Referring to AST, this framework is based on two basic assumptions [16]. The first one refers to the structures embedded in a specific context and defined as rules, resources, and possibilities in a given context [17]. If this assumption is adopted to the context of TMLS, the applied learning methods as well as the service structures can be considered as a potential dimension. They are reflected by the learning environment, the use of IT, and applied learning techniques.

The second basic assumption relates to the design of the learning process. This process view considers the interaction of learners with the learning service structures described above [16], e.g., by means of the learner's adaption to the applied learning methods and materials. The focus on the learning process can be explained by the transfer of these ideas to the field of service research and service systems [20]. Customer integration and simultaneous production and consumption of personoriented services, the so-called uno-actu principle, strengthens the result of a service, e.g., the learning satisfaction for an IT-supported learning service. In this interactive process, the learner thus plays a very important role and should be considered with their individual, cultural differences, which arise from the specific context of the learning service (e.g., the country in which the learning service is provided). Therefore, recent research has considered the learning process and examined procedural factors of learning services centering around the interaction between learners and the learning service [15].

Both assumptions affect the output factors of a learning service, e.g., learning success or the learning satisfaction. In addition, a learning service is always embedded in a certain context. This can, e.g., relate to organizational aspects, or as in the present paper to the cultural aspects that are important in terms of the learning service provision.

\subsection{Culture}

Although culture has been an important research topic in various fields such as anthropology, cross-cultural psychology, and economics for over a hundred years, relevant research is still ongoing [21]. One reason is that culture itself is a complex construct associated with different reference levels. So far, research has mainly focused on national and organizational culture as the main reference levels. Both levels have been regarded as separate research lines focusing on values that distinguish one group from another [22].

National culture is used to distinguish attitudes and behavioral differences between individuals from different countries. Research primarily applies Hofstede's cultural dimensions theory [23] to explain cultural differences [22]. For this purpose, Hofstede originally derived four dimensions of national culture in cooperation with IBM: power distance, individualism-collectivism, masculinityfemininity, and uncertainty avoidance. Long-term orientation and indulgence-restraint were later added to reflect the cultural values of other nations, such as China in terms of long-term orientation [24]. Thus, Table 1 presents a brief definition for each value dimension.
Table 1 Cultural Dimensions according to Hofstede (Source: [25]; [26]; [24])

\begin{tabular}{|c|c|}
\hline Value Dimension & Definition \\
\hline $\begin{array}{l}\text { Individualism- } \\
\text { Collectivism }\end{array}$ & $\begin{array}{l}\text { The extent to which an individual } \\
\text { prioritizes their own benefit over } \\
\text { the benefit of the group and thus } \\
\text { preferably acts as an individual } \\
\text { rather than a member of the group. }\end{array}$ \\
\hline Power Distance & $\begin{array}{l}\text { The extent to which an individual } \\
\text { accepts large differences in power } \\
\text { and inequality as normal. }\end{array}$ \\
\hline $\begin{array}{l}\text { Uncertainty } \\
\text { Avoidance }\end{array}$ & $\begin{array}{l}\text { The extent of risk emphasizing rule } \\
\text { obedience, ritual behavior, and } \\
\text { safety measures accepted by an } \\
\text { individual. }\end{array}$ \\
\hline Masculinity-Femininity & $\begin{array}{l}\text { The extent to which an individual } \\
\text { accepts gender inequality. }\end{array}$ \\
\hline Long-term Orientation & $\begin{array}{l}\text { The extent of long-term orientation } \\
\text { versus short-term orientation } \\
\text { towards the future. }\end{array}$ \\
\hline Indulgence-Restraint & $\begin{array}{l}\text { The extent to which members of a } \\
\text { society control their own desires } \\
\text { and impulses. }\end{array}$ \\
\hline
\end{tabular}

Besides Hofstede, there are several other researchers who have proposed value-based approaches to investigate cultural values of a nation, including Yoo et al. [27] and Schwartz [28].

The other line of research examines cultural values practiced by members of certain organizations. This research area referred to as organizational culture is to be distinguished from national cultural values [24]. According to Schein [29], organizational culture can be distinguished on three characteristic levels, including:

- Artifacts as the topmost and only visible level reflecting structures and processes in organizations.

- One level below exists no longer visible cultural values that are reflected in organizations' core values and common values of organization members.

- At the lowest level are basic assumptions ingrained in an organization.

However, it should be noted here that although these two research lines are often approached separately, national and organizational values are strongly interlinked under certain circumstances [25]. Since the present paper emphasizes the need for an internationalization of TMLS, it further focuses on the understanding of national cultural differences and refers to Hofstede's cultural dimensions described above.

\subsection{Modularization of Services}

In the context of projects, modularization is understood as the division of a whole project into groups. In the context of services however, modularization is understood as the decomposing of such a service into individual elements, namely modules. These combinable module elements are firmly linked to each other and fulfil a specific function as an entity [30].

It is characteristic that modularization is based on two fundamental principles: cohesion and loose coupling [31], with cohesion referring to the intra-module cohesion of the module elements and loose coupling to the intermodule dependency between the individual modules [32]. Loose coupling aims at low dependencies between the individual modules in combination with the following two requirements. When decomposing a service, the chosen interfaces must consider the combination of heavily dependent elements into one module [33]. This causes less dependency between the respective modules. The 
remaining dependencies between the individual modules are then easily detectable. The internal module properties remain invisible from the outside [34]. Cohesion focuses on precisely these internal properties and thus describes the extent of the correlation respectively dependency between the elements within a module. A high cohesion indicates a very similar target function of the individual elements within a module, while simultaneously allowing a high reusability [35]. Specifically, this means that individual service processes can be combined into modules and that new services can then be configured based on these modules. This idea of service modularization and the steps of the service process for module-based and reconfigured services are collectively illustrated in Figure 1.

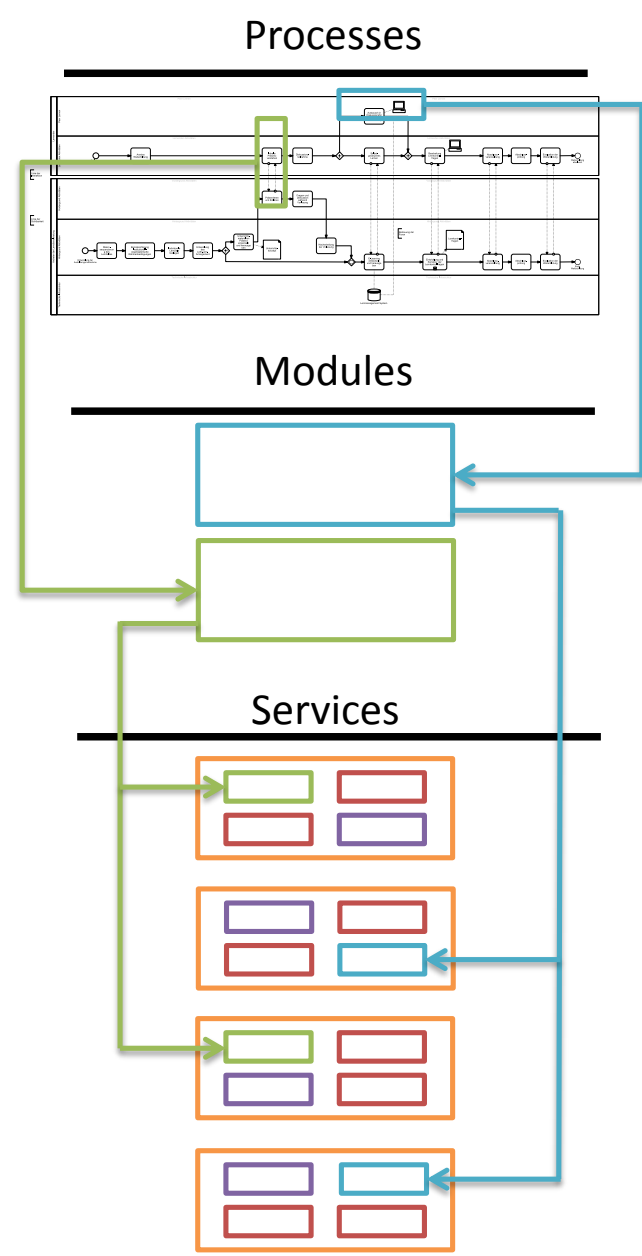

Fig. 1 From Service Process to a Module-based Service

These basic characteristics of modularization conclude the following advantages [36]:

- Reusability not only allows the module to be used across multiple services, but also entails a cost advantage.

- Modularity allows a simple and rapid development of the modules since the individual modules have to be adapted to certain services only.

- Innovations can be applied directly to a specific module in order to create specific competitive advantages.

- The high extent of independency between the modules allows a flexible reconfiguration of services, ensuring a customer-centric mass production.

Since a one-to-one adaptation of a service into a different (cultural) context is often not possible in course of the internationalization of services [10], modularization allows
ICServ2015, 022, v2: 'The efficient p...' the identification of independent and interdependent modules. This can also be applied to the internationalization and thus culture-sensitive reconfiguration of learning services. Since there is a lack of a systematic approach to culture-specific modularization, according starting points will be presented in the following.

\section{NATIONAL CULTURE AS STARTING POINT FOR THE MODULARIZATION OF TMLS}

In order to consider national culture as a starting point for the design and modeling of a service, it will be shown how culture can influence the perception of learning services. Based on this theoretical background, Section 3.2 illustrates how the cultural dependencies of the individual learning service components can be considered by means of modularization in the course of design-oriented research. For this purpose, Section 3.3 points out initial possibilities for a practical implementation by giving an example.

\subsection{The Influence of National Culture on TMLS}

In order to determine the influence of national culture on TMLS, the following sections are based on the already introduced theoretical principles concerning cultural values according to Hofstede. It is assumed that these values have a moderating influence on the service with its individual modules. Referring to the dimension of uncertainty avoidance (UAI), it is assumed that this value will affect the results of the provided learning methods and structures [37]. Here, specific reference is made to the influence of UAl in respect to the use of e-learning components in a learning service. If such components are unknown and therefore new to a learner, they will no longer feel comfortable with a high UAI in this situation. This might be expressed by anxiety, nervousness, and the need for a predictable behavior of the e-learning component [25]. In addition, research results show that UAI is associated with an inhibitory effect on the acceptance of IT artifacts [25, 38]. If these ideas are transferred to the context of TMLS, it can be assumed that this is similar for modules including IT support, for if the learner does not engage such modules, e.g, webbased training for self-regulated learning, the effects of the provided learning methods and structures are to no avail.

Additionally, it is assumed that the learning process is affected by the cultural values of masculinity-femininity (MAS-FEM), individualism-collectivism (IDV-COL), and power distance (PDI). The dimensions of long-term orientation and indulgence-restraint will not be considered regarding their impact on learning services, since there is still need for a theoretical foundation in order to make any assumptions regarding the modularization of learning services in this context. Regarding MAS-FEM, it is assumed that the learning process and thus initiated interaction between lecturer and learner are affected. In masculine cultures, it may be the case that lecturers selectively set good learners apart, thereby preventing interaction with average and below average students. Consequently, it can be assumed that the learning outcomes of these learning groups may be affected adversely [39]. This can also be applied to the value of IDV-COL in a modified form, meaning that collaborative learning in a group is appropriate for collectivist cultures and self-directed learning is more applicable in individualistic cultures [9, 39]. In addition, this paper argues that PDI affects the results of the learning process. In cultures with a high PDI, interaction may be limited during the learning process. This might be the case if a learner does not dare to actively participate in discussions or ask self-directed questions concerning comprehension problems during a 
ICServ2015, 022, v2: 'The efficient p...' vocational training session. From this, it is concluded that a limited interaction negatively affects the output perspective of a learning service.

\subsection{Methodology for a Culture-sensitive Service Modularization}

To allow a systematic and culture-sensitive modularization of services, an according methodology pursuing this goal is presented below. A methodology is the detailed description of a collection of activities [40] allowing the modularization. The activities of the methodology are divided into sequential five steps, which are illustrated in Figure 2.

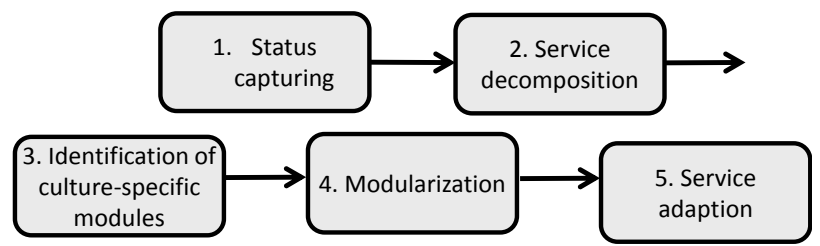

Fig. 2 Methodology for a Culture-sensitive Service Modularization

\section{Status Capturing}

The methodology process starts with a recording of the status quo in order to receive a detailed overview regarding the modularization object [41]. For this purpose, detailed analyses should be carried out by means of empirical research methods, mostly qualitative interviews, observations, and document analyses [42 S. $308 \mathrm{ff}$.]. The according objective is the documentation of the service process, which is used as an input for the next phases of the proposed methodology.

\section{Service Decomposition}

In the second step, namely the decomposition, the process documentation from the first step is used to decompose the service into its individual components at the process level. To formally illustrate this decomposition, this paper refers to a modification of the Business Process Model and Notation (BPMN) in order to provide the necessary information for the next steps.

The necessary modifications in this case relate to the inclusion of the Service Blueprint concept [43]. This is necessary in order to transparently map the interactions of the various stakeholders involved in the process. The typical BPMN pools are used for the according stakeholders, while the lanes of a pool are used to identify front and backstage activities of a stakeholder pool. Therefore, the relevant lanes of interaction (between the pools) and visibility (between the lanes of a pool) are inserted at this point. This will then allow the identification of specific process steps dependent respectively independent of culture. In this context, it is assumed that invisible backstage processes are independent of culture and visible as well as interactive processes are potentially culture-dependent. This approach to learning service design is summarized in Figure 3 . The shaded lanes are therefore potentially culture-dependent.

\section{Identification of Culture-specific Modules}

The identification of culture-specific modules is based on the theoretical principles of cultural conflict [22]. The main assumption of this theory is that cultural values remain unnoticed as long as no cultural gap exists. However, different cultural values cause conflicts and the different nature of certain cultures becomes visible including corresponding consequences.

Therefore, the individual process steps of the process map are first evaluated regarding their importance for the perception of cultural differences by the service consumer respectively learner. After this evaluation, culture-independent and culture-dependent process steps follow.

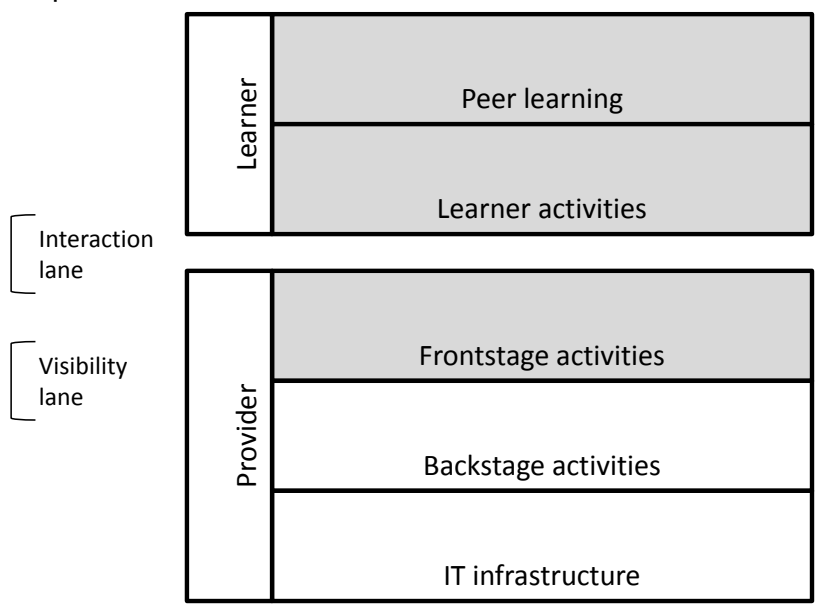

Fig. 3 Service Blueprint Modification

\section{Modularization}

Now, the cultural gaps between different countries providing a service are determined for a specific case. This determination is concluded on the basis of the empirical studies conducted by Hofstede. Following, the individual culture-specific process steps are evaluated regarding the different cultural perceptions by the learner in terms of Hofstede's cultural dimensions.

On this basis follows the culture-sensitive modularization. The individual culture-specific process steps are summarized based on their properties and cultural dependency with other modules. Thus, dependent modules are combined in dependency to specific cultural values. These modules are therefore characterized by a high cohesion and can be loosely coupled with other modules.

In addition, the culture-independent process steps can be summarized as a kind of basic module that is globally recognizable and therefore conducts the core of the learning service. However, it should be noted that a further modularization is also possible at this point, e.g., based on further modularization parameters.

\section{Service Adaptation}

The last step of the culture-sensitive modularization is the adaptation of the service to a culturally different market. For this purpose, the basic modules as well as the modules generating no cultural conflicts are used. Finally, the other culture-specific service components are included in the service configuration. After completing these five steps, the modularization process is completed and the different modules can be configured and offered according to the relevant culture-sensitive context.

\subsection{Culture-sensitive Design of an TMLS by means of Modularization}

To illustrate the first steps towards a culture-sensitive service, the present paper describes the export of an TMLS from Germany to China. For this purpose, the methodological steps presented in Section 3.2 are considered by means of a fictional example.

\section{Status Capturing}

To impose the status quo with respect to the current service provision in Germany, two main steps should be performed: First, on the basis of interviews with the learning service providers. In the present case, lecturers as well as human resource developers are suitable interviewees. In order to conduct a holistic overview on the training, observational studies must be carried out by in-class consultation. Document analyses, e.g., with respect to the learning objectives of a specific training, 
complete this methodology process step in this (fictional) case.

\section{Service Decomposition}

The learning service process is visualized in the source country, based on the status quo imposed in the first step, and decomposed into the individual processes. A simplified process design of a TMLS respectively a vocational training in the present paper is exemplarily illustrated in Figure 4.

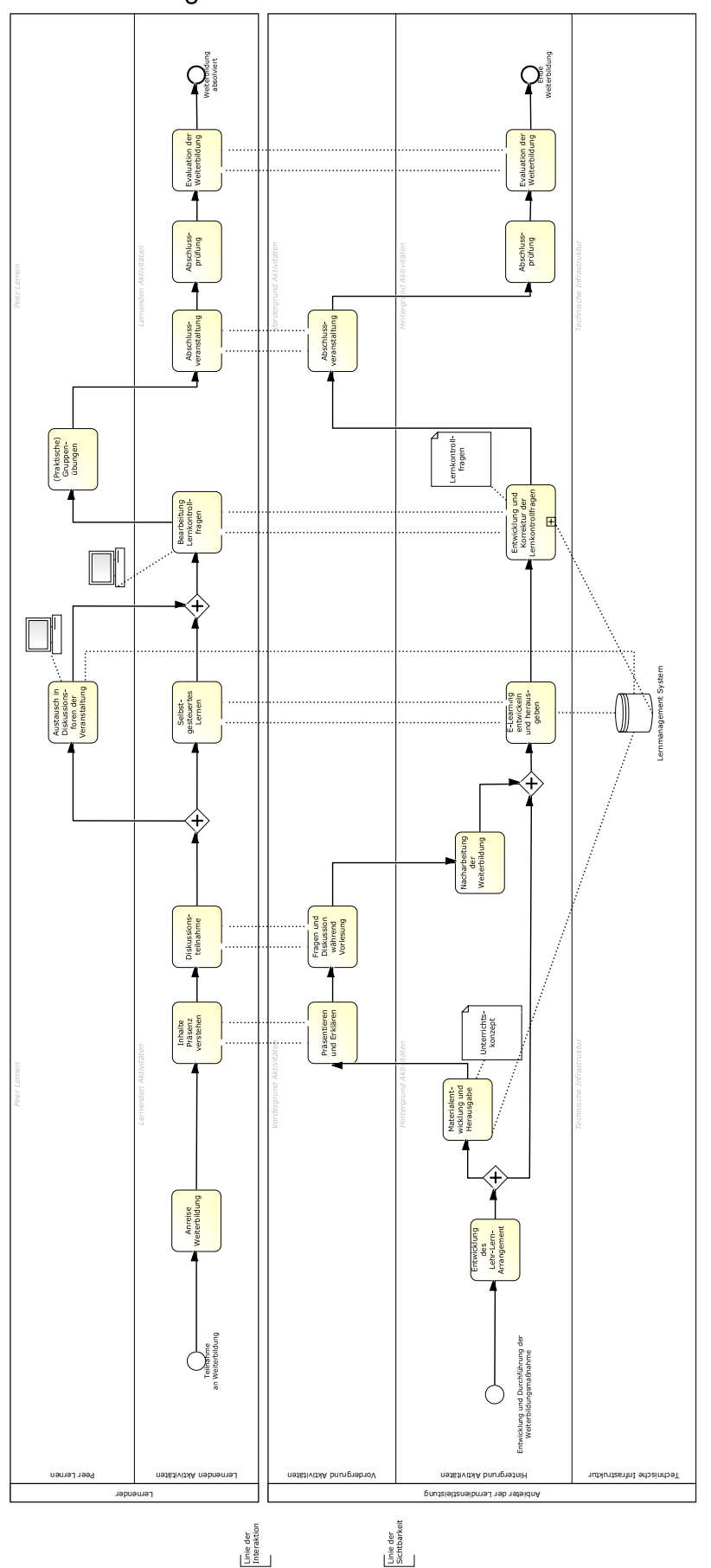

Fig. 4 Process Design of a TMLS

For this purpose, two pools were used to illustrate the sub-activities of the service on the part of the service providers and the learner. The pool regarding the stakeholder of learners consists of two lanes above the interaction lane, meaning that these activities are selfdirected carried out by the learner. The second lane of this pool is used with respect to the activities taking place between different learners. This distinction is already successfully applied in other areas dealing with complex services [44]. In this context, the present paper considers
ICServ2015, 022, v2: 'The efficient p...'

collaborative learning processes such as group discussions. In addition, the provider is taken into account in this process mapping comprising three lanes. Here, the visible (front stage activities) and not directly visible process steps need to be distinguished, as indicated by the visibility lane. The backstage activities as well as the IT infrastructure of the provider are located below this lane.

\section{Identification of Culture-specific Modules}

To facilitate the identification of culture-dependent and thus also culture-independent modules, the process steps within the present process map of the learning service are evaluated regarding cultural dependency. This is determined by whether the consumer of the service respectively the learner perceives cultural differences. The evaluation is carried out on the basis of the service blueprint visualized in the second step, distinguishing between front and backstage activities. Since it can be assumed that the backstage activities cannot be perceived by the learner, they can be combined into basic modules, namely in the present case the development of teaching and learning arrangements (depending on a culture-sensitive configuration of the learning service), the development and editing of learning materials, the post-processing of the vocational training, the development of learning assessments, as well as exams and evaluations.

\section{Modularization}

Now, the cultural gaps between the source country of the service and the target country are determined for further analysis. For this purpose, the present paper considers results by Hofstede [24], who conducted quantitative studies on the basis of the cultural dimensions described in 2.2 in order to identify global cultural differences. The results referring to Germany and China are presented in Figure 5.

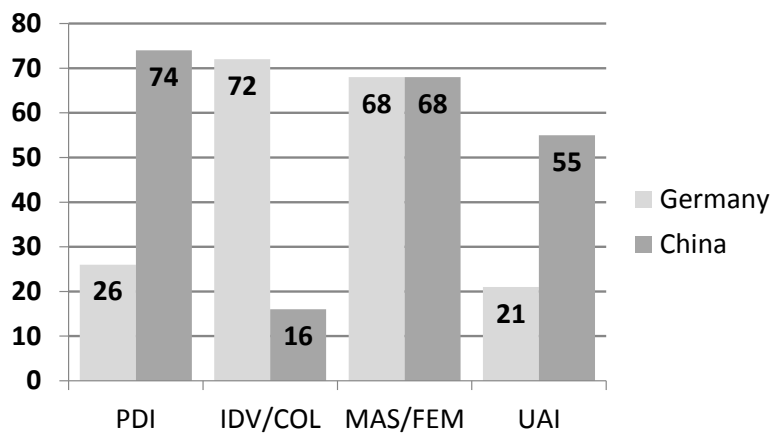

Fig. 5 Cultural Differences between Germany and China (Source: [24])

Based on these empirical findings, cultural differences between Germany and China regarding PDI, IDV-COL, and UAI can be identified, while the values for MAS-FEM are identical for both countries. The next step is now devoted to the evaluation of culture-dependent process steps with respect to cultural conflicts in the process of the TMLS. For this purpose, the theoretical insights regarding the influence of culture on TMLS obtained in Section 3.1 are used. Concerning the present case, this means that the in-class teaching, self-directed learning by means of e-learning, learning assessment by means of elearning, collaborative learning among students in form of an exchange in discussion forums, group assignments, as well as the evaluation in respect to each cultural influence (positive and negative) are evaluated regarding value dimensions respectively value pairs. The according results can be found in Table 2 . 
ICServ2015, 022, v2: 'The efficient p...'

Table 2 Cultural Influence on Culture-specific Processes

\begin{tabular}{ll}
\hline Processes & $\begin{array}{l}\text { Influence Cultural } \\
\text { Dimension }\end{array}$ \\
\hline In-class Teaching & MAS (+) / FEM (-); PDI (-) \\
Self-directed Learning & $\mathrm{COL} \mathrm{(-)} \mathrm{/} \mathrm{IDV} \mathrm{(+);} \mathrm{UAI} \mathrm{(-)}$ \\
Learning Assessment & $\mathrm{COL} \mathrm{(-)} \mathrm{/} \mathrm{IDV} \mathrm{(+);} \mathrm{UAI} \mathrm{(-)}$ \\
$\begin{array}{l}\text { Collaborative Learning by } \\
\text { means of E-Learning }\end{array}$ & $\mathrm{COL} \mathrm{(+)} \mathrm{/} \mathrm{IDV} \mathrm{(-)}$ \\
Group Assignments & $\mathrm{COL} \mathrm{(+)} \mathrm{/} \mathrm{IDV} \mathrm{(-)}$ \\
Evaluation & $\mathrm{MAS}(+) /$ FEM (-) \\
\hline
\end{tabular}

We now use these empirical insights and abstract them to dependency matrices. If there is a culture conflict between two processes, we assign the value "1" two these two processes. Otherwise, if there is no cultural conflict, we assign the value " 0 " to indicate that these two processes have no cultural conflicts. For instance, considering the two processes self-directed learning and the formative learning assessments, we assign the value " 0 " for this specific process couple, because both processes are preferred by individualistic cultures. In contrast, self-directed learning and collaborative learning with E-Learning would induce a cultural conflict and, hence, this process couple would be assigned with the value "1!. Since we draw on the cultural dimensions of Hofstede, we use the original four cultural dimensions for building services modules and, thus, create four dependency matrices that we accumulate in one matrix. This matrix shows the accumulated cultural conflicts across all modules and cultural value dimensions. If there are no or just low cultural conflicts we are able to form a module of the processes, otherwise we do not propose a module.

Based on these results, the formation of three modules is proposed, namely in-class teaching and evaluation (module 1), self-directed learning and learning assessment (module 2), as well as collaborative learning on the basis of e-learning and group assignments (module 3). Regarding these three modules, it is assumed that the individual components do not produce any mutual cultural conflicts and are thus applicable as modules in an according cultural context. Module 3, e.g., constitutes collaborative learning techniques and is therefore suitable for use in collectivist cultures.

\section{Service Adaptation}

First, the basic culture-independent modules are applied in course of the service configuration. The next step is the specific design of the learning service for the particular cultural context without possibly inducing cultural conflicts. In the present case of China, this is achieved by means of modules 1 and 3 .

Further aspects need to be considered during the subsequent implementation and testing phases. While module 1 (in-class teaching and evaluation) does not conclude cultural conflicts with respect to the value pair MAS-FEM and is thus applicable in Germany and China, adaptations concerning the module design need to be considered regarding the different values of PDI in both countries. In the context of this module, vocational training discussions could e.g., be offered by means of IT support, allowing learners not to lose face by anonymously participating in the discussion. In contrast, this kind of adaptation would not be necessary in Germany. Finally, the modularization process would be completed and learning effects could be applied to other cases.

\section{DISCUSSION}

After Chapter 3 presented approaches of systematic modularization for a culture-sensitive service provision, the suitability of such an approach will be discussed below. The systematic modularization facilitates the reusability of modules in general, as well as in a cultural context, respectively culture-independent modules in the present case. Identifying these modules allows for globally standardized basic modules for the export of a (learning) service in order to promote reusability. Besides the usual benefits, such as learning effects and cost benefits, the potential of the possible IT support for such modules is to be mentioned as well. The advantage of innovation across modules provides the possibility to selectively invest in culture-sensitive service modules that are connected to a strong demand, a distinguished inhouse expertise, as well as particularly promising expected competitive advantages. This way, it is also possible to promptly react to culturally determined market needs. Finally, the systematic detection of culturedependent and independent modules allows a flexible reconfiguration, whereby the described service can be easily adapted to the context of other countries and cultures, irrespectively of the example give in Section 3.3. Thus, it can be observed that the Anglo-Saxon export of learning services is very successful due to the provision of modules with small learning units, whereas German educational offers are very inflexible [2]. However, it should be noted that this reconfiguration has its limits. Hence, a learning service is always subject to certain conditions, e.g., that learners achieve specific learning objectives and accordingly take a final exam before obtaining a certification. These conditions must therefore be taken into account in course of the service configuration. The cultural modification of mandatory modules yet allows the consideration of cultural issues. If e-learning modules are necessary, a cultural adaptation of the IT component would be applicable [45]. When dealing with procedural components of the service on the other hand, a culture-sensitive reference modeling of these modules applies [46].

\section{LIMITATIONS AND FUTURE RESEARCH}

The present paper has some limitations and accordingly allows for future research. Although the findings of this paper are theoretically profound, there is still a lack of sufficient substantiated empirical results regarding the influence of individual cultural dimensions on the individual components of a learning service. Although the research results by Hofstede et al. (2010) provide first guidelines for the design of culture-sensitive services, particularly the differences identified in the present paper disclose the limitations of this approach. Thus, it seems unlikely that MAS-FEM are culturally developed alike in Germany and China. Additionally, other study results elaborate on the diversity of Chinese culture and particularly stress the importance of subcultures in a Chinese context [47]. Therefore, an empirical verification on an individual level would be necessary to consider factors such as group or organizational cultures. This is not possible using the results by Hofstede [24]. In addition, the derived methodology has not yet been evaluated accordingly. Therefore, the methodology should eventually be evaluated regarding its suitability for a systematic modularization in the context of designoriented research by means of expert evaluations and experimental settings. Accordingly, this methodology is only a first step towards a holistic culture-sensitive service design. However, first service offerings that are exported from Germany to China show the potential of the proposed method. It should also be noted that culture is only one criterion for modularization among many others. Therefore, it would be worth examining how 
culture behaves as modularization parameter in interdependency with other parameters [48]. Therefore, existing methods for the modularization of complex services should be reinforced in the future and available literature should accordingly be scanned for such modularization approaches in a systematic manner, for instance by considering systematic workshop approaches to identify cultural-dependent modules. Referring to cultural dimensions, the influence of the more recent Hofstede dimensions of long-term orientation and indulgence-restraint remain to be evaluated. There is still a lack of theoretical foundations, which can however be developed on the basis of empirical work described above. Finally, the inclusion of other stakeholders from the learning environment should be considered for further reflection, since it has proved effective in other settings of complex services [49]. Along with this, it should also be noted that the present (fictional) case study is overly simplified in order to convey the basic idea of a culturesensitive service modularization to the reader.

\section{SUMMARY}

The present paper described how the culture-sensitive provision of a service can be implemented based on a systematic application of modularization. To answer the question of how the aspect of culture can be considered in the course of service modularization (RQ1), a theoretical background on culture was given, followed by an illustration of how culture influences TMLS. Additionally, it was shown how culture can be included as a criterion for service modularization based on the theory of cultural conflict. This was followed by the provision of design guidelines for a methodology including culture in the modularization process (RQ2). For this purpose, a methodology consisting of five steps was introduced and illustrated with an exemplary TMLS. Thus, the contribution of this paper lies firstly in the theoretical enhancement regarding modularization theory by inclusion of culture, and secondly in the practical provision of a method.

Hence, the present paper is a first step towards globally providing culture-sensitive services based on modularization. Further planned steps are the evaluation of the methodology in practice and the inclusion of additional criteria for modularization in an international context, because culture is indeed an important construct but still only one among many others.

\section{ACKNOWLEDGEMENTS}

The research presented in this paper was funded by the German Federal Ministry of Education and Research in course of the project kuLtig (www.projekt-kuLtig.de), FKZ 01BEX05A13.

\section{REFERENCES}

[1] iMOVE, Trendbarometer: Exportbranche Aus- und Weiterbildung. Available: https://www.imovegermany.de/cps/rde/xbcr/imove_projekt_de/p_iMO VE Trendbarometer 2013 sicher.pdf.

[2] Fraunhofer MOEZ, Treibende und hemmende Faktoren im Berufsbildungsexport aus Sicht deutscher Anbieter. Available: http://berufsbildungsexportmeta.de/system/publications/documents/000/000/ 001/original/FraunhoferMOEZ_Studie_Treiber_He mmnisse final.pdf? $13710468 \overline{6} 1$.

[3] D. Straub, K. Loch, R. Evaristo, E. Karahanna, and M. Srite, "Toward a Theory-Based Measurement of Culture," Journal of Global Information Management, vol. 10, no. 1, pp. 1323, 2002.

[4] N. Donthu, "Cultural Influences on Service Quality Expectations," Journal of Service Research, vol. 1, no. 2, pp. 178-186, 1998.
ICServ2015, 022, v2: 'The efficient p...'

[5] A. S. Mattila, "The Role of Culture in the Service Evaluation Process," Journal of Service Research, vol. 1, no. 3, pp. 250-261, 1999.

[6] N. Raajpoot, "Reconceptualizing Service Encounter Quality in a Non-Western Context," Journal of Service Research, vol. 7, no. 2, pp. 181-201, 2004.

[7] P. Gerbic, "Chinese learners and computer mediated communication: Balancing culture, technology, and pedagogy," in Proceedings of the 22nd Annual Australian Society for Computers in Learning in Tertiary Education Conference: Balance, Fidelity, Mobility: Maintaining the Momentum, 2005.

[8] S. Hornik and A. Tupchiy, "Culture's Impact on Technology Mediated Learning," Journal of Global Information Management, vol. 14, no. 4, pp. 3156, 2006.

[9] B. Fischer and B. Kopp, "Evaluation of a Western training concept for further education in China," interculture journal, vol. 6, no. 4, pp. 57-76, http://www.interculturejournal.com/index.php/icj/article/view/61, 2007.

[10] M. Schermann, T. Böhmann, M. Prilla, T. Herrmann, and H. Krcmar, "Service Modularization for Customer-Specific Service Design Based on Highly Standardized Services," in Implementing International Services: A Tailorable Method for Market Assessment, Modularization, and Process Transfer, T. Böhmann, W. Burr, T. Herrmann, and H. Krcmar, Eds, Wiesbaden: Gabler Verlag / Springer Fachmedien Wiesbaden $\mathrm{GmbH}$, Wiesbaden, 2012, pp. 101-118.

[11] A. R. Hevner, S. T. March, J. Park, and S. Ram, "Design science in information systems research," MIS Quarterly, vol. 28, no. 1, pp. 75-105,

http://dl.acm.org/citation.cfm?id=2017212.201721 7, 2004.

[12] O. Arazy, N. Kumar, and B. Shapira, "A TheoryDriven Design Framework for Social

Recommender Systems," Journal of the

Association for Information Systems, vol. 11, no. 9, http://aisel.aisnet.org/jais/vol11/iss9/2, 2010.

[13] A. Gehlert, M. Schermann, K. Pohl, and H. Krcmar, "Towards a Research Method for Theorydriven Design Research," Wirtschaftinformatik Proceedings 2009, http://aisel.aisnet.org/wi2009/42, 2009.

[14] M. Alavi and D. E. Leidner, "Research Commentary: Technology-Mediated Learning--A Call for Greater Depth and Breadth of Research," Information Systems Research, vol. 12, no. 1, pp. 1-10, 2001.

[15] S. Gupta and R. Bostrom, "An Investigation of the Appropriation of Technology-Mediated Training Methods Incorporating Enactive and Collaborative Learning," Information Systems Research, vol. 24, no. 2, pp. 454-469, 2013.

[16] $\quad$ Comprehensive Theoretical Model," Journal of the Association for Information Systems, vol. 10, no. 9, pp. 686-714, 2009.

[17] G. DeSanctis and M. S. Poole, "Capturing the complexity in advanced technology use: Adaptive structuration theory," Organization Science, vol. 5, no. 2, pp. 121-147, 1994.

[18] P. Bitzer and A. Janson, "Towards a Holistic Understanding of Technology-Mediated Learning Services - a State-of-the-Art Analysis," ECIS 2014 Proceedings, 2014.

[19] A. Janson and Thiel de Gafenco, Marian, "Engaging the Appropriation of Technology- 
ICServ2015, 022, v2: 'The efficient p...' mediated Learning Services - A Theory-driven Design Approach," ECIS 2015 Proceedings, 2015.

[20] S. Kwan and Min, Jae, H, "An Evolutionary Framework of Service Systems: Presented at the International Conference on Service Science Beijing, China, April 17-18, 2008," 2008.

[21] T.-F. Kummer, J. M. Leimeister, and M. Bick, "On the Importance of National Culture for the Design of Information Systems," Business \& Information Systems Engineering, vol. 4, no. 6, pp. 317-330, 2012.

[22] D. E. Leidner and T. Kayworth, "Review: A Review of Culture in Information Systems Research: Toward a Theory of Information Technology Culture Conflict," MIS Quarterly, vol. 30, no. 2, pp. 357-399, http://www.jstor.org/stable/25148735, 2006.

[23] G. Hofstede, Culture's consequences: International differences in work-related values: Sage Publications, Inc, 1980.

[24] G. H. Hofstede, G. J. Hofstede, and M. Minkov, Cultures and organizations: Software of the mind: intercultural cooperation and its importance for survival, 3rd ed. New York: McGraw-Hill, 2010.

[25] M. Srite and E. Karahanna, "The Role of Espoused National Cultural Values in Technology Acceptance," MIS Quarterly, vol. 30, no. 3, pp. 679-704, http://www.jstor.org/stable/25148745, 2006.

[26] B. Yoo, N. Donthu, and T. Lenartowicz, "Measuring Hofstede's five dimensions of cultural values at the individual level: Development and validation of CVSCALE," Journal of International Consumer Marketing, vol. 23, no. 3-4, pp. 193210, 2011.

[27] E. T. Hall, Beyond culture: Random House Digital, Inc, 1977.

[28] S. H. Schwartz, "Individualism-Collectivism: Critique and Proposed Refinements," Journal of Cross-Cultural Psychology, vol. 21, no. 2, pp. 139-157, 1990.

[29] E. H. Schein, "Organizational culture," American psychologist, vol. 45, no. 2, pp. 109-119, 1990.

[30] M. A. Schilling, "Toward a General Modular Systems Theory and Its Application to Interfirm Product Modularity," Academy of management review, vol. 25, no. 2, pp. 312-334, 2000.

[31] H. Balzert, Lehrbuch der Software-Technik Software-Entwicklung. Heidelberg: Lehrbuch der Software-Technik - Software-Entwicklung, 2000.

[32] C. Peters and J. M. Leimeister, "TM" - A Modularization Method for Telemedical Services: Design and Evaluation," in 21st European Conference on Information Systems (ECIS), Utrecht, Netherlands, 2013.

[33] A. Bask, M. Lipponen, M. Rajahonka, and M. Tinnilä, "Framework for modularity and customization: service perspective," Journal of Business \& Industrial Marketing, vol. 26, no. 5, pp. 306-319, 2011.

[34] D. L. Parnas, "On the criteria to be used in decomposing systems into modules," Commun. ACM, vol. 15, no. 12, pp. 1053-1058, 1972.

[35] C. Y. Baldwin and K. B. Clark, "Managing in an age of modularity," Harvard Business Review, vol. 75, no. 5, pp. 84-93, 1997.

[36] T. Böhmann and H. Krcmar, "Modulare Servicearchitekturen," in Service Engineering, H.J. Bullinger and A.-W. Scheer, Eds, Berlin/Heidelberg: Springer-Verlag, 2006, pp. 377-401.
[37] F. W. Swierczek and C. Bechter, "Cultural Features of e-Learning," in Learning and Instruction in the Digital Age, J. M. Spector, D. Ifenthaler, P. Isaias, Kinshuk, and D. Sampson, Eds, Boston, MA: Springer US, 2010, pp. 291308.

[38] D. W. Straub, "The Effect of Culture on IT Diffusion: E-Mail and FAX in Japan and the U.S," Information Systems Research, vol. 5, no. 1, pp. 23-47, 1994.

[39] G. Hofstede, "Cultural differences in teaching and learning," International Journal of Intercultural Relations, vol. 10, no. 3, pp. 301-320, 1986.

[40] S. Brinkkemper, "Method engineering: engineering of information systems development methods and tools," Information and Software Technology, vol. 38, no. 4, pp. 275-280, 1996.

[41] H. Dubberly, S. Evenson, and R. Robinson, "On modeling the analysis-synthesis bridge model," interactions, vol. 15, no. 2, p. 57, 2008.

[42] J. Bortz, Bortz-Döring, and N. Döring, Forschungsmethoden und Evaluation: Für Human- und Sozialwissenschaftler ; mit 87 Tabellen, 4th ed. Heidelberg: Springer-MedizinVerl, 2009.

[43] G. L. Shostack, "Designing services that deliver," Harvard Business Review, vol. 62, no. 1, pp. 133139, 1984.

[44] C. Peters, C. Elm, M. Söllner, and J. M. Leimeister, "Blueprint-driven Telemedicine Process Modeling - The Interdisciplinary Development and Evaluation of a Modeling Language for Telemedical Services," in Annual AIS SIG Services Pre-ICIS Workshop 2014, Auckland, New Zealand, 2014.

[45] K. Reinecke and A. Bernstein, "Knowing what a User Likes: A Design Science Approach to Interfaces that Automatically Adapt to Culture," MIS Quarterly, vol. 37, no. 2, pp. 427-A11, http://search.ebscohost.com/login.aspx?direct=tru e\&db=buh\&AN=87371385\&site=ehost-live, 2013.

[46] M. Schermann, M. Prilla, T. Böhmann, H. Krcmar, and T. Herrmann, "Designing Services as Adaptable Reference Models," in Implementing International Services: A Tailorable Method for Market Assessment, Modularization, and Process Transfer, T. Böhmann, W. Burr, T. Herrmann, and H. Krcmar, Eds, Wiesbaden: Gabler Verlag / Springer Fachmedien Wiesbaden $\mathrm{GmbH}$, Wiesbaden, 2012, pp. 276-292.

[47] M. Martinsons and D. Ma, "Sub-Cultural Differences in Information Ethics across China: Focus On Chinese Management Generation Gaps," Journal of the Association for Information Systems, vol. 10, no. 11 http://aisel.aisnet.org/jais/vol10/iss11/2, 2009.

[48] C. Peters, "Together They are Strong - The Quest for Service Modularization Parameters," Proceedings of the 22nd European Conference on Information Systems (ECIS). Tel Aviv, Israel, 2014.

[49] C. Peters and J. M. Leimeister, "Modellierung telemedizinischer Dienstleistungen mit der Blueprint-driven Telemedicine Process Modeling Language," in Produktivität von Dienstleistungen, W. Schultze and K. Möller, Eds, Germany: Springer, 2014. 